\title{
Enteric fever in two vaccinated travellers to Latin America
}

\section{Andrée-Anne Beaulieu MD, Andrea K. Boggild MD}

Competing interests: None

This article has been peer reviewed.

Correspondence to: Dr. Andrea K. Boggild, andrea.boggild@utoronto.ca

CMAJ 2011. DOI:10.1503 /cmaj.101320 declared.

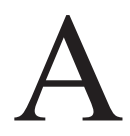
previously healthy 24-year-old woman (patient A) and her partner, a previously healthy 25-year-old man (patient B), presented to our clinic with fever after travelling in Latin America. Patient A reported an 11-day history of daily fever to $40^{\circ} \mathrm{C}$, chills, diffuse muscle aches and joint pains, bilateral throbbing headache, insomnia and watery, nonbloody diarrhea up to 12 times daily. Patient $\mathrm{B}$ presented with a 12-day history of daily fevers to $41^{\circ} \mathrm{C}$, chills, headache and extreme fatigue.

Three days before their presentation, they had returned from a six-month trek through rural and urban areas of Peru, Ecuador, Chile, Argentina and Bolivia. They had sought travel advice before their trip and had received vaccinations for typhoid fever (injectable Vi polysaccharide vaccine), yellow fever and hepatitis A. They had received atovaquone/proguanil for malaria prophylaxis, to which they had been nonadherent.

The last week of their trip had been spent in Lima, Peru, where they had both begun to feel ill. Six days before the onset of illness, they had spent several days in a remote village in the jungle near Rurrenabaque, Bolivia, living among local residents, eating local foods and drinking local water. They had also been bitten extensively by mosquitoes and possibly other arthropods. On day four of patient A's illness (day five of patient B's illness), they sought care at a local hospital in Lima. Thick and thin blood films were used to

\section{- KeY POINTS}

- Enteric fever is a common cause of fever in the returned traveller; enteric fever caused by Salmonella enterica serotype Typhi ("typhoid fever") is clinically indistinguishable from the illness caused by Salmonella enterica serotypes Paratyphi A, B or C ("paratyphoid fever").

- Fever is often persistent, usually abating four to six days after the start of treatment.

- Fluoroquinolones are the preferred treatment for enteric fever, unless the illness has originated in south or southeast Asia where resistance is high.

- Vaccines licensed for the prevention of typhoid fever confer only partial protection against Salmonella Typhi, although the oral formulation may also provide partial protection against Salmonella Paratyphi B; as such, a history of immunization against typhoid should not preclude enteric fever as a diagnosis in returned travellers with fever. screen for malaria, and serum agglutination antibody tests were used to screen for typhoid and paratyphoid fevers and brucellosis. The results of the patients' blood tests were normal, with the exception of mild thrombocytopenia seen in the sample from patient A. They were discharged from the hospital with a probable diagnosis of dengue fever and were given no specific treatment. Both patients continued to feel ill, with spiking temperatures, headache and fatigue. Patient A also continued to have myalgia and arthralgia, though her diarrhea began to improve. By the time patient $\mathrm{A}$ arrived in Canada (eight days after the start of her illness), she was having five diarrheal stools per day. Both patients had loss of appetite but were drinking large amounts of water.

On examination, the patients appeared ill, although both were afebrile, alert and oriented. Patient A's blood pressure was 100/50 mm Hg; patient B's blood pressure was $90 / 60 \mathrm{~mm} \mathrm{Hg}$. Physical examination showed that patient A had mild tenderness to palpation of the left upper quadrant of the abdomen without clinical evidence of splenomegaly, as well as a diffuse, blotchy, erythematous, macular rash across her upper and lower extremities, chest and abdomen. A physical examination of patient $B$ was unremarkable.

Laboratory investigations from their initial visit to our clinic (day 1) are summarized in Table 1. Notably, the results from thick and thin blood smears and dipstick assays screening for malaria were negative. The patients returned to our clinic immediately after providing samples of their blood. Because the results of the tests for malaria were negative, each patient was given a 10-day course of ciprofloxacin for empiric management of presumed enteric fever. They were asked to return to the clinic the next day (follow-up 1, day 2) for another malaria screening and reassessment. The results of laboratory investigations done during each of their three follow-up visits are summarized in Table 1.

By the third day of the course of ciprofloxacin, both patients began to feel better, reporting peak temperatures of $38-38.5^{\circ} \mathrm{C}$ in the previous 
Table 1: Results of laboratory investigations for a previously healthy 24-year-old woman (patient A) and 25-year-old man (patient B) who presented with fever after travelling in South America

\begin{tabular}{|c|c|c|c|c|c|c|}
\hline \multirow[b]{2}{*}{ Investigation } & \multirow[b]{2}{*}{$\begin{array}{l}\text { Normal } \\
\text { values }\end{array}$} & \multirow[b]{2}{*}{ Patient } & \multicolumn{4}{|c|}{ Visit to clinic } \\
\hline & & & $\begin{array}{l}\text { Initial visit on } \\
\text { day } 1\end{array}$ & $\begin{array}{l}\text { Follow-up on } \\
\text { day } 2\end{array}$ & $\begin{array}{l}\text { Follow-up on } \\
\text { day } 7\end{array}$ & $\begin{array}{l}\text { Follow-up } \\
\text { on day } 14\end{array}$ \\
\hline \multirow{2}{*}{$\begin{array}{l}\text { Hemoglobin, } \\
\text { g/L }\end{array}$} & $120-140$ & $A$ & 136 & 123 & 123 & 121 \\
\hline & $140-160$ & B & 145 & 136 & - & 138 \\
\hline WBC, $10^{9} / \mathrm{L}$ & $3.5-11.0$ & $A$ & 3.0 & 4.2 & 3.9 & 4.4 \\
\hline \multirow[t]{2}{*}{ Platelets, $10^{9} / \mathrm{L}$} & \multirow[t]{2}{*}{$150-400$} & $A$ & 135 & 143 & 309 & 388 \\
\hline & & B & 279 & 270 & - & 473 \\
\hline \multirow[t]{2}{*}{ AST, U/L } & \multirow[t]{2}{*}{$<37$} & $A$ & 380 & 301 & 54 & 23 \\
\hline & & B & 82 & 75 & 45 & 24 \\
\hline ALP, U/L & $20-140$ & B & 59 & 52 & 60 & 65 \\
\hline \multirow{2}{*}{$\begin{array}{l}\text { Bilirubin, } \\
\mu \mathrm{mol} / \mathrm{L}\end{array}$} & \multirow[t]{2}{*}{$<20$} & $A$ & 8 & 7 & 5 & 6 \\
\hline & & B & 10 & 11 & 11 & 11 \\
\hline \multirow{2}{*}{$\begin{array}{l}\text { Creatinine, } \\
\mu \mathrm{mol} / \mathrm{L}\end{array}$} & \multirow[t]{2}{*}{$45-100$} & $A$ & 62 & 58 & 54 & - \\
\hline & & B & 76 & 98 & 66 & - \\
\hline \multirow[t]{2}{*}{ Sodium, $\mu \mathrm{mol} / \mathrm{L}$} & \multirow[t]{2}{*}{$135-145$} & $A$ & 126 & 129 & 137 & - \\
\hline & & B & 129 & 131 & 138 & - \\
\hline \multirow{2}{*}{$\begin{array}{l}\text { Potassium, } \\
\mu \mathrm{mol} / \mathrm{L}\end{array}$} & \multirow[t]{2}{*}{$3.5-4.5$} & A & 3.4 & 4.1 & 4.2 & - \\
\hline & & B & 5 & 4 & 4.8 & - \\
\hline & & B & Pending & Pending & Pending & $\begin{array}{l}\text { IgM nonreactive, IgG } \\
\text { nonreactive }\end{array}$ \\
\hline Rickettsial & Negative & A & Pending & Pending & Pending & Negative \\
\hline serology & & B & Pending & Pending & Pending & Negative \\
\hline Urinalysis & Normal & $A$ & Normal & - & - & - \\
\hline & & B & Normal & - & - & - \\
\hline Stool culture $†$ & Negative & $A$ & Pending & Negative & - & $\begin{array}{l}\text { S. enterica ser. } \\
\text { Paratyphi B (repeat } \\
\text { stool culture) }\end{array}$ \\
\hline & & B & Pending & Salmonella species & S. enterica Paratyphi & $\begin{array}{l}\text { S. enterica ser. } \\
\text { Paratyphi B }\end{array}$ \\
\hline Chest & Normal & A & Normal & - & - & - \\
\hline radiography & & B & Normal & - & - & - \\
\hline Abdominal & Normal & A & - & - & Normal & - \\
\hline ultrasound & & B & - & - & - & - \\
\hline $\begin{array}{l}\text { Note: ALP = alkaline } \\
\text { immunoglobulin G; } \\
\text { *Susceptible to amo } \\
\text { †The results of follo }\end{array}$ & $\begin{array}{l}\text { hosphatase, ALT } \\
\text { M = immunoglob } \\
\text { cillin, ciprofloxac } \\
\text { up stool culture }\end{array}$ & $\begin{array}{l}=\text { alanine tr } \\
\text { ulin } \mathrm{M} ; \mathrm{WB} \\
\text { in and trime } \\
\text { obtained th }\end{array}$ & $\begin{array}{l}\text { ansaminase, } A S T=a \\
C=\text { white blood cell. } \\
\text { thoprim/sulfametho } \\
\text { ree months post-tre }\end{array}$ & $\begin{array}{l}\text { artate transaminase, GN } \\
\text { zole. } \\
\text { ment were negative for }\end{array}$ & $\begin{array}{l}\text { gram-negative bacilli, } \mathrm{Hb}= \\
\text { th patients. }\end{array}$ & noglobin; IgG = \\
\hline
\end{tabular}


48 hours. Their chills had stopped and their headaches and myalgia had resolved, as had patient A's diarrhea. Both patients still had loss of appetite and felt fatigued, and patient A continued to have mild tenderness on the left side of her abdomen. By the fourth day of treatment, the patients were no longer febrile. By the seventh day of treatment, both patients had regained their appetites and energy levels. Fourteen days after starting treatment, the patients felt normal. The final diagnosis was enteric fever due to Salmonella enterica serotype Paratyphi B.

\section{Discussion}

Enteric fever due to either Salmonella enterica serotype Typhi ("typhoid fever") or Salmonella enterica serotypes Paratyphi A, B or C ("paratyphoid fever"), is one of the more common causes of fever in the returned traveller. In singlecentre and multicentre observational studies of illness in returned travellers, enteric fever has been shown to account for $2 \%-7 \%$ of such illnesses, and it is generally among the top five specific etiologic diagnoses (Box 1). ${ }^{1-6}$ This foodborne and waterborne illness has highest relative risks among people travelling to visit friends and relatives on the Indian subcontinent ${ }^{-1,6-8}$ however, travellers to all developing countries, regardless of purpose, are at theoretical risk (Figure 1). ${ }^{9}$

A history of travel to the Indian subcontinent in a febrile returned traveller should raise suspicion of enteric fever. Of 416 cases of imported typhoid in the United Kingdom over a three-year
Box 1: Conditions that commonly present as fever in a returned traveller ${ }^{1-6}$

- Malaria (20\%-30\%)

- Acute traveller's diarrhea or gastroenteritis $(10 \%-20 \%)$

- Respiratory tract infection (10\%-15\%)

- Dengue fever (5\%)

- Enteric fever due to Salmonella enterica serotypes Typhi or Paratyphi (2\%-7\%)

- Infections of the skin and soft tissue (2\%-11\%)

- Rickettsioses (3\%)

- Acute infection of the urinary tract or sexually transmitted infection (2\%-3\%)

- Viral hepatitis (3\%)

- Mononucleosis- or viral-like syndrome $(4 \%-25 \%)$

period, 70\% were from India and Pakistan. ${ }^{10}$ In the observational analysis by Freedman and colleagues, typhoid fever was a major contributor to systemic febrile illness without an identifiable organ focus among people who had returned from southcentral Asia.?

Of 149 patients with documented S. enterica ser. Paratyphi A in the United States in 20052006 for whom epidemiologic information was known, $90 \%$ had recently travelled to south Asia. ${ }^{11}$ In a number of Asian countries, S. enterica ser. Paratyphi A is becoming increasingly responsible for enteric fever - in some regions, it accounts for up to $50 \%$ of instances of the disease. ${ }^{12}$ However, S. enterica ser. Paratyphi B was reported in five American travellers, four of whom had recently visited Latin America. ${ }^{11}$

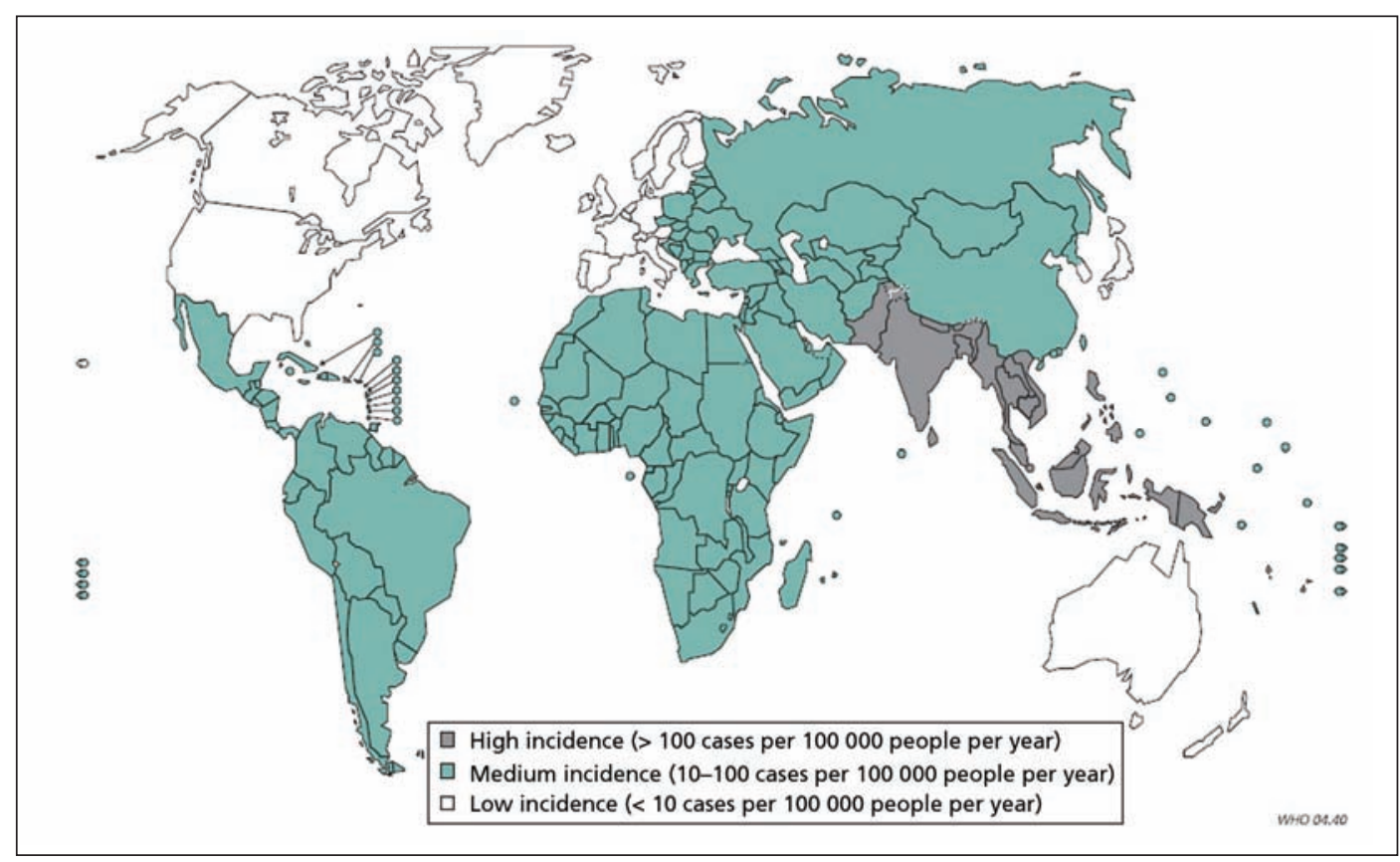

Figure 1: Geographic distribution of typhoid fever. Reproduced with permission from Crump et al. ${ }^{9}$ 


\section{Are typhoid and paratyphoid clinically distinguishable?}

Enteric fever caused by $S$. enterica ser. Paratyphi was formerly believed to cause a milder clinical picture than typhoid fever, although this is now known to be incorrect. ${ }^{13,14}$ Recent reports have shown that paratyphoid fever is clinically indistinguishable from typhoid fever, ${ }^{13,14}$ and that almost two-thirds of patients with enteric fever caused by $S$. enterica ser. Paratyphi A required admission to hospital. ${ }^{11}$

After ingesting an infectious dose of S. enterica ser. Typhi (> 1000 organisms) or S. enterica ser. Paratyphi in water or food, an asymptomatic incubation period of 7-14 days typically ensues. ${ }^{15}$ Fever heralds the onset of bacteremia, which is often accompanied by frontal headache, myalgia, anorexia, nausea, vomiting, abdominal pain and constipation or diarrhea, as seen in our patients. Fever becomes high and is sustained over time. Enteric fever may be complicated by gastrointestinal bleeding in $10 \%$ of patients who have been unwell for more than two weeks before the start of treatment (Box 2).$^{15}$ Gastrointestinal perforation and encephalopathy are more severe sequelae of untreated typhoid fever; fortunately, these outcomes occur in less than $3 \%$ of patients. ${ }^{15}$ Relapse of illness two to three weeks after fever has abated occurs in up to $10 \%$ of patients. ${ }^{15}$

Chronic fecal carriage, defined as excretion of S. enterica in the stool for at least one year, occurs in $1 \%-4 \%$ of patients, and is more common among patients with gallstones, ${ }^{15}$ though the risk is lowest after treatment with fluoroquinolones. The eradication of these organisms is important from a public health perspective, but also because chronic carriage of $S$. enterica ser. Typhi (and Paratyphi A) has a small associated risk of biliary carcinoma. ${ }^{16}$

\section{What tests are used to confirm enteric fever?}

Enteric fever should be excluded, along with competing diagnoses (Box 1),${ }^{1-6}$ in returned travellers with history of fever, regardless of their immunization status. A culture of the bone marrow is the gold-standard diagnostic test for enteric fever; ${ }^{17}$ however, owing to its practical limitations and invasiveness, it is rarely performed. Rather, cultures of the blood and stool, though less sensitive than cultures of the bone marrow, are usually used for diagnostic and epidemiologic purposes. Blood cultures yield positive results from $60 \%-80 \%$ of patients with acute enteric fever, and results of stool cultures are positive $30 \%$ of the time. ${ }^{15}$ Serology plays no role in the diagnosis of enteric fever in resourced settings. Results of laboratory investiga- tions that are compatible with a diagnosis of enteric fever include leukopenia, thrombocytopenia, and mild-to-moderate elevation of hepatic transaminase levels. ${ }^{17}$ However, the results of investigations, including the complete blood count, are often normal, even for a patient who looks ill.

Cultures of the blood and stool take time, and their results may be falsely negative. When the index of suspicion is high and a diagnosis of malaria has been ruled out, empiric administration of antibiotics (Table 2), the choice of which is based on epidemiology, is a reasonable approach.

\section{What are the best options for management?}

Enteric fever is usually treated with either oral or parenteral antibiotics (Table 2). Severe enteric fever characterized by gastrointestinal bleeding or perforation, neuropsychiatric complications (as outlined in Box 2) or cardiovascular complications such as shock, myocarditis or endocarditis, necessitates inpatient management of care and treatment with parenteral antibiotics. In addition, patients with severe enteric fever complicated by delirium, stupor, coma or shock have been shown to benefit from dexamethasone in randomized controlled trials..$^{15,18}$

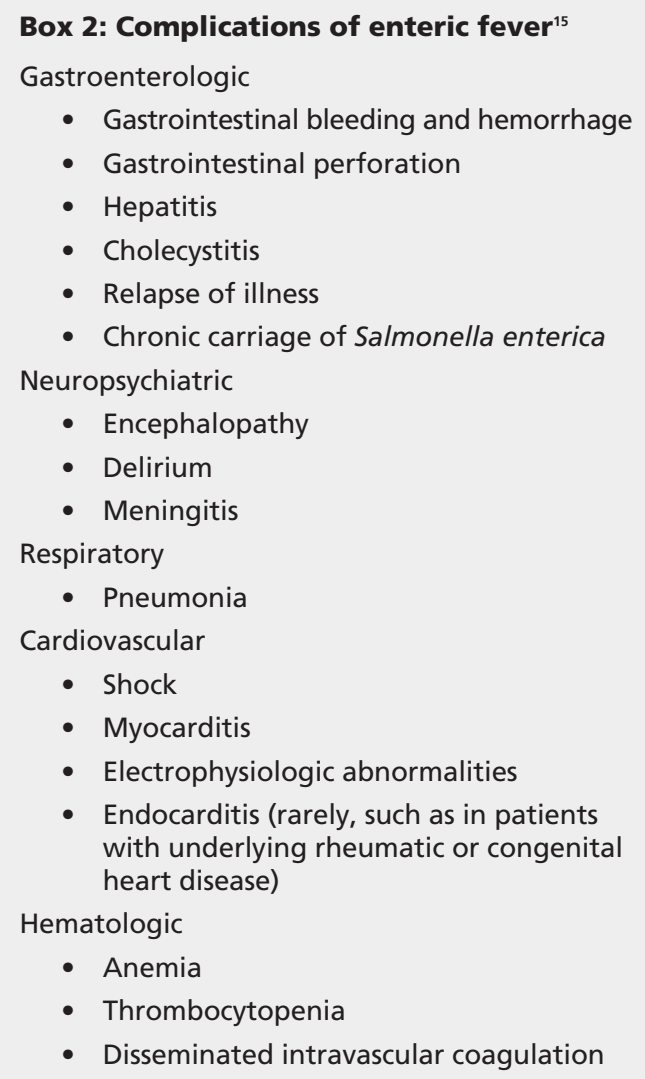
with underlying rheumatic or congenital heart disease) 
Table 2: Options for the antibiotic treatment of enteric fever caused by Salmonella enterica serotypes Typhi or Paratyphi $i^{15,17}$

\begin{tabular}{|c|c|c|}
\hline $\begin{array}{l}\text { Susceptibility profile of } \\
\text { organism }\end{array}$ & Drug & $\begin{array}{l}\text { Duration of } \\
\text { treatment, } d\end{array}$ \\
\hline \multicolumn{3}{|l|}{$\begin{array}{l}\text { Uncomplicated enteric } \\
\text { fever }\end{array}$} \\
\hline \multirow[t]{3}{*}{ Fully susceptible } & Ciprofloxacin & $5-10$ \\
\hline & Amoxicillin & 14 \\
\hline & $\begin{array}{l}\text { Trimethoprim/ } \\
\text { sulfamethoxazole }\end{array}$ & 14 \\
\hline \multirow[t]{2}{*}{ Multidrug resistant* } & Ciprofloxacin & $5-10$ \\
\hline & Cefixime & $7-14$ \\
\hline \multirow[t]{2}{*}{ Quinolone resistant } & Azithromycin & $5-7$ \\
\hline & Cefixime & $7-14$ \\
\hline \multicolumn{3}{|l|}{$\begin{array}{l}\text { Severe or complicated } \\
\text { enteric fever (parenteral } \\
\text { antibiotics)† }\end{array}$} \\
\hline \multirow[t]{3}{*}{ Fully susceptible } & Ciprofloxacin & $10-14$ \\
\hline & Ampicillin & 14 \\
\hline & $\begin{array}{l}\text { Trimethoprim/ } \\
\text { sulfamethoxazole }\end{array}$ & 14 \\
\hline \multirow[t]{2}{*}{ Multidrug resistant* } & Ciprofloxacin & $10-14$ \\
\hline & Ceftriaxone & $10-14$ \\
\hline \multirow[t]{3}{*}{ Quinolone resistant } & Ceftriaxone & $10-14$ \\
\hline & Cefotaxime & $10-14$ \\
\hline & Ciprofloxacin $\ddagger$ & 14 \\
\hline \multicolumn{3}{|c|}{$\begin{array}{l}\text { *Resistant to ampicillin, chloramphenicol and trimethoprim/sulfamethoxazole; more } \\
\text { common in isolates from south and southeast Asia. } \\
\text { tOnce the patient is able to tolerate oral medications, step down to a corresponding oral } \\
\text { agent, such as ciprofloxacin, cefixime, trimethoprim/sulfamethoxazole or azithromycin, } \\
\text { depending on the susceptibility profile of the organism, is appropriate. } \\
\text { tHigh doses of fluoroquinolones for a longer period (e.g. } 750 \mathrm{mg} \text { of ciprofloxacin twice daily } \\
\text { for } 14 \mathrm{~d} \text { ) may be used to treat enteric fever caused by a quinolone-resistant isolate with the } \\
\text { caveat that the fever may not subside as quickly. Quinolone resistance is more common in } \\
\text { isolates from south and southeast Asia. }\end{array}$} \\
\hline
\end{tabular}

Antimicrobial resistance is an increasing concern in the management of enteric fever. Up to $87 \%$ of isolates of S. enterica ser. Paratyphi from south Asia that were tested at the Centers for Disease Control and Prevention in 2005-2006 showed resistance to nalidixic acid, ${ }^{11}$ which confers reduced clinical response to fluoroquinolones. Multidrug resistance (i.e., resistance to ampicillin, chloramphenicol and trimethoprim/ sulfamethoxazole) and resistance to nalidixic acid is particularly common among strains of S. enterica ser. Typhi from south and southeast Asia. In general, multidrug resistance among isolates of S. enterica ser. Paratyphi is rare. ${ }^{19}$

Fluoroquinolones have emerged as the favoured antibiotic in susceptible cases of enteric fever because they reduce the length of time the fever lasts, they have high clinical cure rates, and they show a reduced risk of long-term fecal carriage of the Salmonella organisms. ${ }^{15}$ Systematic reviews of randomized controlled trials have shown higher rates of clinical failure among patients given treatment with ceftriaxone versus fluoroquinolones, which is the basis for using parenteral fluoroquinolone as the first line of treatment for complicated cases. ${ }^{20}$ In instances of fluoroquinolone resistance, systematic reviews of randomized controlled trials support the use of azithromycin orally as a practical first-line option for uncomplicated cases. ${ }^{21}$ Randomized controlled trials of treatment for typhoid fever have shown that fevers typically abate four to seven days after appropriate treatment has started; ${ }^{15}$ failure of a fever to diminish quickly is not an indication to change antibiotics.

Table 3: Vaccines for typhoid that have been licensed for use in Canada ${ }^{22}$

\begin{tabular}{|c|c|c|c|c|}
\hline Formulation & $\begin{array}{l}\text { Route of administration and } \\
\text { schedule }\end{array}$ & $\begin{array}{l}\text { Recommended minimum } \\
\text { age of patient }\end{array}$ & Contraindications & $\begin{array}{l}\text { Booster } \\
\text { schedule }\end{array}$ \\
\hline \multicolumn{5}{|l|}{$\begin{array}{l}\text { Live attenuated } \\
\text { Ty21a }\end{array}$} \\
\hline $\begin{array}{l}\text { Vivotif (Berna } \\
\text { Biotech) }\end{array}$ & 1 capsule, orally, every $2 \mathrm{~d} \times 4$ doses & $\geq 5 \mathrm{yr}$ & $\begin{array}{l}\text { Immune suppression, } \\
\text { concurrent use of } \\
\text { antibiotics, } \\
\text { inflammatory bowel } \\
\text { disease }\end{array}$ & Every 5 yr \\
\hline $\begin{array}{l}\text { Vivotil (Berna } \\
\text { Biotech) }\end{array}$ & 1 sachet, orally, every $2 \mathrm{~d} \times 3$ doses & $\geq 3 \mathrm{yr}$ & $\begin{array}{l}\text { Immune suppression, } \\
\text { concurrent use of } \\
\text { antibiotics, } \\
\text { inflammatory bowel } \\
\text { disease }\end{array}$ & Every 5 yr \\
\hline
\end{tabular}




\section{How efficacious are currently available vaccines?}

Two vaccine formulations, one oral (Ty21a) and one injectable (Vi polysaccharide), are licensed for prevention of enteric fever and confer partial protection against $S$. enterica ser. Typhi (Table 3). ${ }^{22}$ A systematic review and meta-analysis showed that the cumulative three-year efficacy of Ty21a is $51 \%$ (95\% confidence interval [CI] 36\%-62\%) under circumstances of ongoing exposure; the corresponding efficacy for the $\mathrm{Vi}$ polysaccharide vaccine is $55 \%$ (95\% CI $30 \%-$ $70 \%) .{ }^{23}$ The Ty21a live oral vaccine has also been shown to confer some protection against $S$. enterica ser. Paratyphi B (Table 3), with a protective efficacy approaching $49 \%$ in randomized controlled trials. ${ }^{24}$ Salmonella enterica ser. Paratyphi lacks the Vi capsular antigen, which is the likely explanation for why the injectable Vi vaccine does not confer protection. Conversely, S. enterica ser. Paratyphi shares several epitopes, including $\mathrm{O}$-antigen epitopes, with the live attenuated organism contained in the oral vaccine. Thus, although the oral vaccine has a slightly less convenient dosing schedule (i.e., several capsules over many days), it has an advantage in terms of its scope of efficacy compared with the injectable Vi formulations.

Strict adherence to food and water hygiene may prevent transmission of enteric fever to travellers; however, such vigilance is difficult for long-term travellers to rural areas of the developing world. Thus, vaccination should be recommended for most travellers to tropical and subtropical destinations.

Given that the efficacy of vaccination is limited, a history of immunization against typhoid should not preclude exclusion of enteric fever as a diagnostic possibility in returned travellers with fever, and the limitations of these vaccines should be emphasized in the pretravel setting. Although the two travellers described in this report had received the injectable Vi polysaccharide vaccine, which lacks efficacy against S. enterica ser. Paratyphi, they had eaten and drunk local foods and water under the expectation of protection against enteric fever. They were therefore surprised by the diagnosis.

The experience of these two patients underscores the importance of taking a full travel and epidemiologic history when returned travellers present with fever. Enteric fever remains a common cause of fever in returned travellers, even for those who report having been immunized.

\section{References}

1. Wilson ME, Weld LH, Boggild A, et al. Fever in returned travelers: results from the GeoSentinel Surveillance Network. Clin Infect Dis 2007;44:1560-8.

2. Bottieau E, Clerinx J, Schrooten W, et al. Etiology and outcome of fever after a stay in the tropics. Arch Intern Med 2006;166:1642-8.

3. Doherty JF, Grant AD, Bryceson AD. Fever as the presenting complaint of travelers returning from the tropics. OJM 1995;88:277-81.

4. O'Brien D, Tobin S, Brown GV, et al. Fever in returned travelers: review of hospital admissions for a 3-year period. Clin Infect Dis 2001:33:603-9.

5. Parola P, Soula G, Gazin P, et al. Fever in travelers returning from tropical areas: prospective observational study of 613 cases hospitalised in Marseilles, France, 1999-2003. Travel Med Infect Dis 2006;4:61-70.

6. Klein JL, Millman GC. Prospective, hospital-based study of fever in children in the United Kingdom who had recently spent time in the tropics. BMJ 1998;316:1425-6.

7. Freedman DO, Weld LH, Kozarsky PE, et al. Spectrum of disease and relationship to place of exposure in ill returned travelers. $N$ Engl J Med 2006;354:119-30.

8. Keller A, Frey M, Schmid H, et al. Imported typhoid fever in Switzerland, 1993 to 2004. J Travel Med 2008;15:248-51.

9. Crump JA, Luby SP, Mintz ED. The global burden of typhoid fever. Bull World Health Organ 2004;82:346-53.

10. Cooke FJ, Day M, Wain J, et al. Cases of typhoid fever imported into England, Scotland and Wales, 2000-2003. Trans $R$ Soc Trop Med Hyg 2007;101:398-404.

11. Gupta SK, Medalla F, Omondi MW, et al. Laboratory-based surveillance of Paratyphoid fever in the United States: travel and antimicrobial resistance. Clin Infect Dis 2008;46:1656-63.

12. Ochiai RL, Acosta CJ, Danovaro-Holliday MC, et al. A study of typhoid fever in five Asian countries: disease burden and implications for control. Bull World Health Organ 2008;86:260-8.

13. Fangtham M, Wilde H. Emergence of Salmonella paratyphi $A$ as a major cause of enteric fever: need for early detection, preventive measures, and effective vaccines. J Travel Med 2008;15:344-50.

14. Maskey AP, Day JN, Phung QT, et al. Salmonella enterica serovar Paratyphi A and S. enterica serovar Typhi cause indistinguishable clinical syndromes in Kathmandu, Nepal. Clin Infect Dis 2006;42:1247-53.

15. Parry CM, Hien TT, Dougan G, et al. Typhoid fever. $N$ Engl J Med 2002;347:1770-82.

16. Nath G, Singh H, Shukla VR. Chronic typhoid carriage and carcinoma of the gall-bladder. Eur J Cancer Prev 1997;6:557-9.

17. Bhutta ZA. Current concepts in the diagnosis and treatment of typhoid fever. BMJ 2006:333:78-82

18. Hoffman SL, Punjabi NH, Kumala S, et al. Reduction of mortality in chloramphenicol-treated severe typhoid fever by high-dose dexamethasone. N Engl J Med 1984;310:82-8.

19. Parry CM, Threlfall EJ. Antimicrobial resistance in typhoidal and nontyphoidal salmonellae. Curr Opin Infect Dis 2008;21:531-8.

20. Thaver D, Zaidi AKM, Critchley JA, et al. Fluoroquinolones for treating typhoid and paratyphoid fever (enteric fever). Cochrane Database Syst Rev 2008;4:CD004530.

21. Effa EE, Bukirwa H. Azithromycin for treating uncomplicated typhoid and paratyphoid fever (enteric fever). Cochrane Database Syst Rev 2008;4:CD006083.

22. Public Health Agency of Canada. Typhoid vaccine. In: Canadian immunization guide, 7th ed. Ottawa (ON): The Agency; 2006. Available: www.phac-aspc.gc.ca/publicat/cig-gci/p04-typh-eng.php (accessed 2011 Jun. 15).

23. Fraser A, Paul M, Goldberg E, et al. Typhoid fever vaccines: systematic review and meta-analysis of randomized controlled trials. Vaccine 2007;25:7848-57.

24. Levine MM, Ferreccio C, Black RE, et al. Ty21a live oral typhoid vaccine and prevention of paratyphoid fever caused by Salmonella enterica serovar Paratyphi B. Clin Infect Dis 2007;45:S24-8.

Affiliations: From the Department of Microbiology and Infectious Diseases (Beaulieu), University of Sherbrooke, Sherbrooke, Que.; and the Tropical Disease Unit (Bogglid), Division of Infectious Diseases, Department of Medicine, University Health Network - Toronto General Hospital, University of Toronto, Toronto, Ont.

Contributors: Andrée-Anne Beaulieu and Andrea Boggild conceived of, wrote and critically appraised this manuscript. 